\title{
Temperature stress in arbuscular mycorrhizal fungi: a test for adap- tation to soil temperature in three isolates of Funneliformis mosseae from different climates
}

\author{
Mayra E. Gavito ${ }^{1}$ and Concepción Azcón-Aguilar ${ }^{2}$ \\ ${ }^{1}$ Centro de Investigaciones en Ecosistemas, Universidad Nacional Autónoma de México. Apartado Postal 27-3. Santa \\ María de Guido. CP 58090. Morelia, Michoacán, Mexico. Fax (52) 4433222719. \\ ${ }^{2}$ Departamento de Microbiología del Suelo y Sistemas Simbióticos, Estación Experimental del Zaidín, CSIC. C/Profesor \\ Albareda 1, E-18008 Granada, Spain \\ e-mail:mgavito@oikos.unam.mx.
}

\begin{abstract}
It has become urgent to explore the potential stimulations or constraints that increasing and fluctuating temperatures derived from climate change may impose on the mycorrhizal symbiosis. We conducted a study to compare the soil temperature response curves $\left(6,12,18\right.$, and $\left.24^{\circ} \mathrm{C}\right)$ of three isolates of Funneliformis mosseae from different regions and climates (Finland, Denmark, Spain), to test if the isolates from cold environments were able to grow better at lower temperatures and the isolates from warmer environments grew better at higher temperatures. The results provided clear evidence suggesting no adaptation to soil temperature in these AMF isolates. All isolates showed reduced development and especially very little external mycelium growth at 6 and $12^{\circ} \mathrm{C}$ regardless of the temperatures they normally experienced in their original habitats and all showed similar increasing development with increasing soil temperature. These results suggest that AMF have a narrow window to develop in cold regions of the world where temperatures below $15{ }^{\circ} \mathrm{C}$ prevail which ought to be well exploited, especially in agroecosystems where management is aimed at improving crop performance and soil quality. With proper management, if temperatures continue to increase, mycorrhizal development and mycorrhizal benefit might also increase in cold regions.
\end{abstract}

Key words: adaptation, climate, mycorrhiza, soil, stress, temperature

\section{Introduction}

The influence of temperature on arbuscular mycorrhizal fungi (AMF) is little understood (Fitter et al. 2000) although temperature is the component of environmental change that may have the strongest direct impact on these fungi, plant performance and the $\mathrm{C}$ cycle. In this important and increasingly relevant context, it has become urgent to explore and understand the potential stimulations or constraints that the rapidly changing temperatures may impose on these symbiotic fungi. For most other organisms, it is more or less accepted that they are either adapted to grow and function at the climatic conditions that predominate in their environments or that they persist by growing only during short periods when specific favourable conditions prevail. Whether AMF species or AMF ecotypes encompass mainly one or both types of organisms is unknown. However, AMF are so ubiquitous that there is a general belief that these organisms have adapted to grow in most environments of the world, being able to grow and function within a very wide temperature range.

The review by Staddon et al. (2002), reports that intraradical mycorrhizal colonization increased in most studies when temperature increased between $5^{\circ} \mathrm{C}$ and $37^{\circ} \mathrm{C}$. Although some previous reports indicate 


\section{AGRICULTURAL AND FOOD SCIENCE}

M. Gavito \& C. Azcón-Aguilar (2012) 21: 2-11

adaptation of native AMF isolates to tolerate extreme temperatures in their environments (Grey 1981), others studies do not. Low temperatures $\left(5{ }^{\circ} \mathrm{C}-15{ }^{\circ} \mathrm{C}\right)$ reduced root colonization (Daniels-Hetrick and Bloom 1984, Gavito et al. 2003), extraradical hyphae development (Gavito et al. 2003, 2005), P uptake (Wang et al. 2002; Liu et al. 2004) and symbiotic efficiency (Kytoviita 2005). Unfortunately, few of those studies measured the development of both the intraradical and the extraradical phases of the mycorrhizal mycelium thereby limiting our understanding of their temperature dependency.

The extraradical AM mycelium supports most of the functions for a mutualistic symbiosis. Once formed and established in soil, it is very resistant to low temperatures and can reinitiate growth and function in the spring after months under freezing temperatures (Addy et al. 1998). Very little is known, however, about its initial development and functioning when soil temperature is either low $\left(<10^{\circ} \mathrm{C}\right)$ or high $(>30$ ${ }^{\circ} \mathrm{C}$ ) for long periods in the growing season. Some studies have demonstrated that isolates and AMF native communities from cold regions showed marked growth reductions below $20^{\circ} \mathrm{C}$, especially of the external mycelium (Gavito et al. 2003, Gavito et al. 2005, Liu et al. 2004).

Heinemeyer and Fitter (2004) observed that local warming only of the extraradical mycelium from 12 ${ }^{\circ} \mathrm{C}$ to $20^{\circ} \mathrm{C}$ stimulated hyphal growth but in a system where both plant and fungus were exposed to the warming treatment. Increasing the temperature did not affect the development of one isolate of Glomus mosseae beyond its stimulating effect on host plant growth. This result suggested that despite being able to respond independently to a temperature change, the governing controlling factor in fungal development was the growth of the host plant. Soil warming in field experiments established in natural communities measuring showed, on the other hand, contradictory positive and negative effects on intraradical and extraradical mycorrhizal development, likely due to our inability to distinguish mycorrhizal from other fungal hyphae and to confounding, concurrent changes in vegetation (Rillig et al. 2002, Heinemeyer et al. 2003, Staddon et al. 2003).

The sensitiveness of AMF to temperature changes may have strong implications in our understanding of the contribution of the arbuscular mycorrhizal symbiosis to plant nutrition, soil aggregation and exploitation, and $\mathrm{C}$-cycling in regions of the world where soil temperatures below $20^{\circ} \mathrm{C}$ or above $40^{\circ} \mathrm{C}$ prevail during the growing season. Clearly, more studies surveying genetic and plastic variability among these fungi are needed to fully understand the extent at which temperature might be limiting their growth and function in different environments.

We conducted a study to compare the temperature response curves of three isolates of Funneliformis mosseae from different regions and climates to test if the isolates from cold environments were able to grow better at lower temperatures and the isolates from warmer environments grew better at higher temperatures. That is, we tested if there was environmental adaptation in these isolates.

\section{Materials and methods}

We used a complete randomized block factorial design with two factors: Funneliformis mosseae isolate (originated from Finland, Denmark, or Spain), and soil temperature $\left(6,12,18\right.$, and $24{ }^{\circ} \mathrm{C}$ ), and five replicates per treatment. A loamy soil with pH 8.1, 1.81\% organic matter, $2.5 \mathrm{mg} \mathrm{N} \mathrm{kg}^{-1}$ and $6.2 \mathrm{mg} \mathrm{NaHCO}$-extractable $\mathrm{P} \mathrm{kg}^{-1}$ was collected at Estación Experimental del Zaidín's experimental field (Granada, Spain). The soil was sieved through $1 \mathrm{~cm}$ mesh, steam-sterilized and aerated for two days. The soil was mixed with quartz sand 1:1 w:w to facilitate mycelium extraction. Eight-cm diameter PVC tubes cut into 30-cm long sections and closed at the bottom with nylon mesh and a rubber band, were used as pots and filled with $700 \mathrm{~g}$ of soil-sand mixture and $50 \mathrm{~g}$ of the appropriate mycorrhizal inoculum. 


\section{AGRICULTURAL AND FOOD SCIENCE}

M. Gavito \& C. Azcón-Aguilar (2012) 21: 2-11

We worked with three isolates of Funneliformis mosseae (Nicol. \& Gerd.) C. Walker \& Schuessler. The isolate from Finland (isolate BEG 57, original geographic location $61^{\circ} 50^{\prime} \mathrm{N}, 25^{\circ} 10^{\prime} \mathrm{E}$ ), was chosen because it was isolated from a cold environment with a cryic soil temperature regime, with mean annual soil temperature $0-8^{\circ} \mathrm{C}$ and mean summer soil temperature below $15^{\circ} \mathrm{C}$ at $50 \mathrm{~cm}$ depth, usually experiencing below zero temperatures in the winter months close to soil surface (Yli-Halla and Mokma 1998, http://www.mm.helsinki. fi/core/data.htm ). F. mosseae BEG 57 was isolated in 1989 and propagated under mild soil temperatures five times before our experiment. The isolate from Denmark (BEG 85, original geographic location $55^{\circ} 40^{\prime} \mathrm{N}$, $12^{\circ} 18^{\prime} \mathrm{E}$ ) was isolated from a slightly milder environment falling in the frigid soil temperature regime with a slightly warmer winter and mean summer soil temperature above $15^{\circ} \mathrm{C}$ at $50 \mathrm{~cm}$ depth but rarely reaching freezing temperatures during the winter or temperatures above $20^{\circ} \mathrm{C}$ during the summer (Pilegaard et al. 2001, http://www.mm.helsinki.fi/core/data.htm, Baldocchi et al., 2005). Soil temperatures closer to the surface can however become much higher than the summer mean and experience large fluctuations through the day. F. mosseae BEG 85 was first collected in 1995 and propagated under mild soil temperatures an uncertain number of cycles but not higher than six, since the lab of origin routinely propagates its collection every year or second year. The isolate from southern Spain (BEG 124, original geographic location $37^{\circ} 42^{\prime} \mathrm{N}$, $4^{\circ} 11^{\prime} \mathrm{W}$ ) originated from a thermic soil temperature regime with winter and summer mean temperatures often differing by more than $15^{\circ} \mathrm{C}$ and reaching above $25^{\circ} \mathrm{C}$ in the summer (Delgado et al. 2007, MorenoRueda et al. 2009). We did not find a comparable data set to those available for Finland and Denmark soils for this region and published reports are often estimates from air temperatures, not direct measurements. Measurements taken three times a week at 16:00 h in the agricultural field at Estación Experimental del Zaidín in Granada, Spain between December 2002 and February 2004 showed temperatures above $35^{\circ} \mathrm{C}$ for several hours during the day at $5 \mathrm{~cm}$ depth during July and August with maximum recorded temperature of $41^{\circ} \mathrm{C}$ in the summer and minimum temperature of $6^{\circ} \mathrm{C}$ in the winter (M. E. Gavito, personal observations). Thus, the isolate from Spain was the one experiencing the widest soil temperature range and largest soil temperature fluctuations throughout the year. F. mosseae BEG 124 was first collected in 1996 and propagated under mild soil temperatures an uncertain number of cycles but, as explained for isolate BEG 85 , not higher than six times since the lab of origin routinely propagates its collection every year or second year.

The isolates were propagated with Sorghum bicolor L. and Trifolium subterraneum L. in pots in the greenhouse for 20 weeks to obtain a uniform inoculum source for the experiment. The PVC pots were filled with $700 \mathrm{~g}$ of the soil-sand mixture previously mixed with $50 \mathrm{~g}$ inoculum consisting of root pieces and soil from the propagation pots of the corresponding isolate. In a pilot experiment, this amount of inoculum (7.1\%) was found to be required to achieve equal intraradical colonization with the three isolates within three weeks at room temperature. The tubes were watered by weight to $85 \%$ of the measured soil water holding capacity and sown with four seeds of subterranean clover (Trifolium subterraneum L.) that were thinned to two after emergence. The tubes were placed in air cooled/heated chambers designed to maintain the soil temperature treatments $\left(6,12,18\right.$, and $\left.24^{\circ} \mathrm{C}\right)$. The chambers were located in a controlled environment growth room at $24^{\circ} \mathrm{C}$ day $/ 18^{\circ} \mathrm{C}$ night, $14 \mathrm{~h}$ photoperiod and $200 \mu \mathrm{mol} \mathrm{m} \mathrm{s}^{-1}$. Since the $24^{\circ} \mathrm{C}$ treatment was the same as the set day temperature in the growth room the pots from this treatment were not placed in cooling chambers and followed the temperature regime in the growth room. The pots were introduced in holes drilled on the lids of the cooling chambers and were hanging from the top by a plastic ring attached to the tube so that the soil was inside the chamber and the plant was outside. Therefore, only soil was exposed to the chamber temperature treatments and shoots experienced the same environmental conditions in the growth room. The soil temperatures were monitored continuously with commercial minimum/maximum/ average-function thermometers with two sensors that were buried in two of the pots of each chamber to ensure the set temperatures were achieved and maintained during the experiment. The minimum/maximum/average- values were recorded every morning and afternoon and the actual soil temperature means calculated from these measurements for the entire duration of the experiment were: 1) $6{ }^{\circ} \mathrm{C}$ treatment, 


\section{AGRICULTURAL AND FOOD SCIENCE}

M. Gavito \& C. Azcón-Aguilar (2012) 21: 2-11

$6.03 \pm 1.11^{\circ} \mathrm{C}$ day and $5.88 \pm 0.73{ }^{\circ} \mathrm{C}$ night, 2) $12{ }^{\circ} \mathrm{C}$ treatment, $11.85 \pm 1.32{ }^{\circ} \mathrm{C}$ day and $11.93 \pm 0.24{ }^{\circ} \mathrm{C}$ night, 3) $18{ }^{\circ} \mathrm{C}$ treatment, $18.12 \pm 0.97^{\circ} \mathrm{C}$ day and $17.58 \pm 0.18{ }^{\circ} \mathrm{C}$ night, 4) $24^{\circ} \mathrm{C}$ treatment, $23.90 \pm 1.02$ ${ }^{\circ} \mathrm{C}$ day and $21.3 \pm 0.65^{\circ} \mathrm{C}$ night.

Pots were watered by weight every second day and arranged in blocks within the soil chamber to minimize position effects.

After 92 days the plants were harvested, shoots were cut and dried to constant weight. Soil samples were taken after thorough mixing and frozen for storage until measuring extraradical hyphae development. The roots were washed, blotted, weighed, and a sample was taken to determine mycorrhizal colonization. The rest of the roots were also dried and weighed. The root sample was temporarily stored in ethanol, and later stained as in Kormanick and Graw (1982). Mycorrhizal colonization was quantified with the magnified intersections method (McGonigle et al. 1990). Two to four $\mathrm{g}$ of soil from thawed samples were weighed and fungal hyphae were extracted, stained, collected in membrane filters and hyphal length was determined by microscopical examination as in Jakobsen et al. (1992).

Statistical analyses were performed with Statistix 7.0 Software. ANOVA was used to test for fungal isolate, soil temperature and block effects. Tukey's post- hoc tests were conducted to assess differences among treatment means. Data sets for the analyses were transformed as required to meet the normal distribution and homogeneity of variances assumptions of ANOVA. Results are presented in their original scale of measurement and differences were considered significant at $p<0.05$.

\section{Results}

Soil temperature treatments had significant effects on all plant biomass and fungal development variables but there were significant interactions of the soil temperature and isolate treatments only for fungal development variables (Table 1).

Table 1. F -values and probabilities of significance for the main effects and factor interaction from two-way ANOVA analyses. Data transformations are specified when required. Probabilities of significance: ${ }^{*}<0.05,{ }^{* *}<0.005,{ }^{* * *}<0.00005$, ns $=$ not significant.

\begin{tabular}{llll}
\hline Variable & $\begin{array}{l}\text { Isolate } \\
2 \mathrm{df}^{1}\end{array}$ & $\begin{array}{l}\text { Soil temperature } \\
3 \mathrm{df}\end{array}$ & $\begin{array}{l}\text { Interaction } \\
6 \mathrm{df}\end{array}$ \\
\hline Plant biomass $(\log )$ & $0.47 \mathrm{~ns}$ & $<0.0005^{* * *}$ & $0.32 \mathrm{~ns}$ \\
$\begin{array}{l}\text { Shoot: root ratio }(\log ) \\
\text { Root biomass }(\log )\end{array}$ & $0.0001^{* * *}$ & $<0.0005^{* * *}$ & $0.15 \mathrm{~ns}$ \\
$\begin{array}{l}\text { Root biomass with mycorrhizal } \\
\text { colonisation }(\log )\end{array}$ & $0.003^{* *}$ & $<0.0005^{* * *}$ & $0.33 \mathrm{~ns}$ \\
$\begin{array}{l}\text { Intraradical colonisation percent- } \\
\text { age }\end{array}$ & $<0.0005^{* * *}$ & $<0.0005^{* * *}$ & $0.0197 *$ \\
Extraradical hyphae length density & $0.004^{* *}$ & $<0.0005^{* * *}$ & $<0.0005^{* * *}$ \\
\hline
\end{tabular}

${ }^{1} \mathrm{df}=$ degrees of freedom 


\section{AGRICULTURAL AND FOOD SCIENCE}

M. Gavito \& C. Azcón-Aguilar (2012) 21: 2-11

Shoot and total biomass increased from 6 to $12{ }^{\circ} \mathrm{C}$ and had their highest values at 18 and $24^{\circ} \mathrm{C}$ (Figs. $1 \mathrm{~A}-\mathrm{C}$ ), whereas root biomass was equally low at 6 and $12{ }^{\circ} \mathrm{C}$ and increased at 18 and further at $24^{\circ} \mathrm{C}$ (Figs. 1D-F).

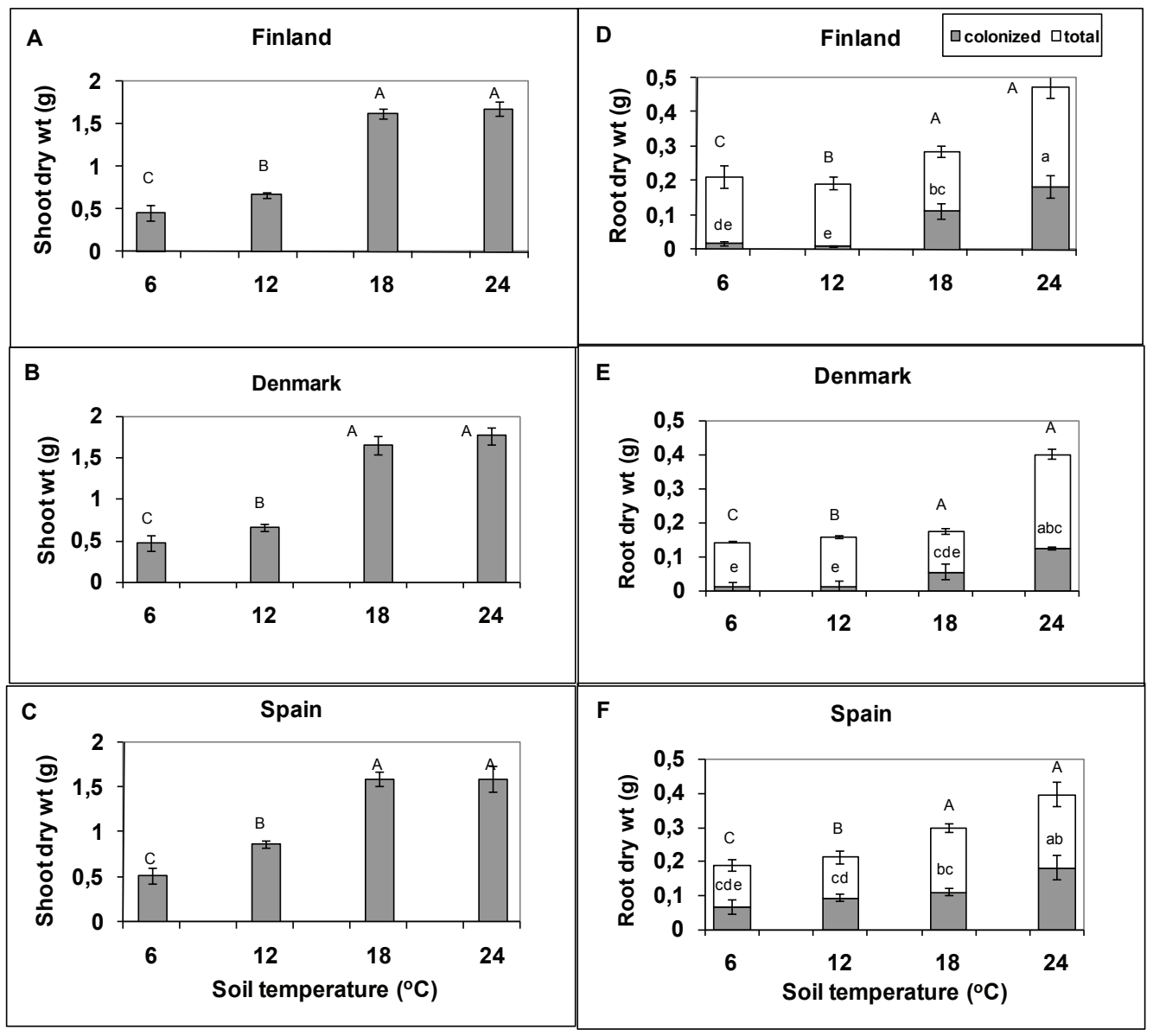

Fig. 1. Clover shoot (A-C) and root (D-F biomass at harvest when inoculated with the three different isolates of Funneliformis mosseae and grown at four soil temperatures. The root biomass that became colonized by each isolate is indicated within the root biomass bar. Means ( $\mathrm{S}$ E) marked with different letters were significantly different at $p<0.05$. Significant soil temperature effects are marked with capital letters whereas significantly different means for isolate $\mathrm{x}$ soil temperature treatment interactions are marked with small letters.

Root biomass was slightly but significantly lower when the plants were inoculated with the Danish isolate and, given that the shoot biomass was similar in all treatments, the shoot:root ratio was slightly higher for this treatment (Fig. 2A). The shoot:root ratio increased steadily from 6 to $18{ }^{\circ} \mathrm{C}$ but dropped at $24^{\circ} \mathrm{C}$ (Fig. 2B). 


\section{AGRICULTURAL AND FOOD SCIENCE}

M. Gavito \& C. Azcón-Aguilar (2012) 21: 2-11

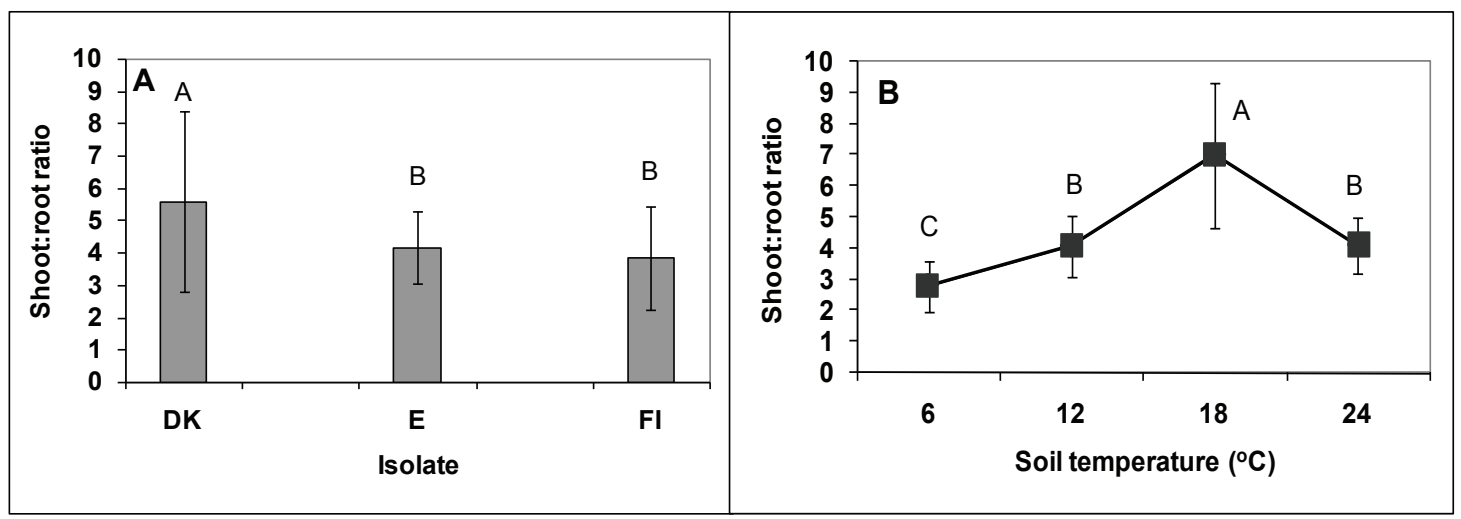

Fig. 2. Mean (+ SE) shoot:root ratios for the main effects of $A M F$ isolate $(A)$ and soil temperature $(B)$. $D K=$ isolate from Denmark, $\mathrm{E}=$ isolate from Spain, and $\mathrm{FI}=$ isolate from Finland. Significant differences are marked with capital letters and

The proportion of the root system that became colonized at 6 and $12{ }^{\circ} \mathrm{C}$ was under $20 \%$ with the Finnish and the Danish isolates but reached up to $40 \%$ with the Spanish isolate (Figs. $1 d-f$ ), as expected from the small differences in root biomass and the mycorrhizal colonization percentages measured at these low temperatures (Fig. 3A). However, the difference observed in intraradical colonization of the Spanish isolate at 6 and $12{ }^{\circ} \mathrm{C}$ was not observed in the development of extraradical mycelium (Fig. 3B). All isolates showed very little external mycelium growth at $6{ }^{\circ} \mathrm{C}$ over the background values measured in the soil before the experiment and all showed similar increasing development with increasing soil temperature.

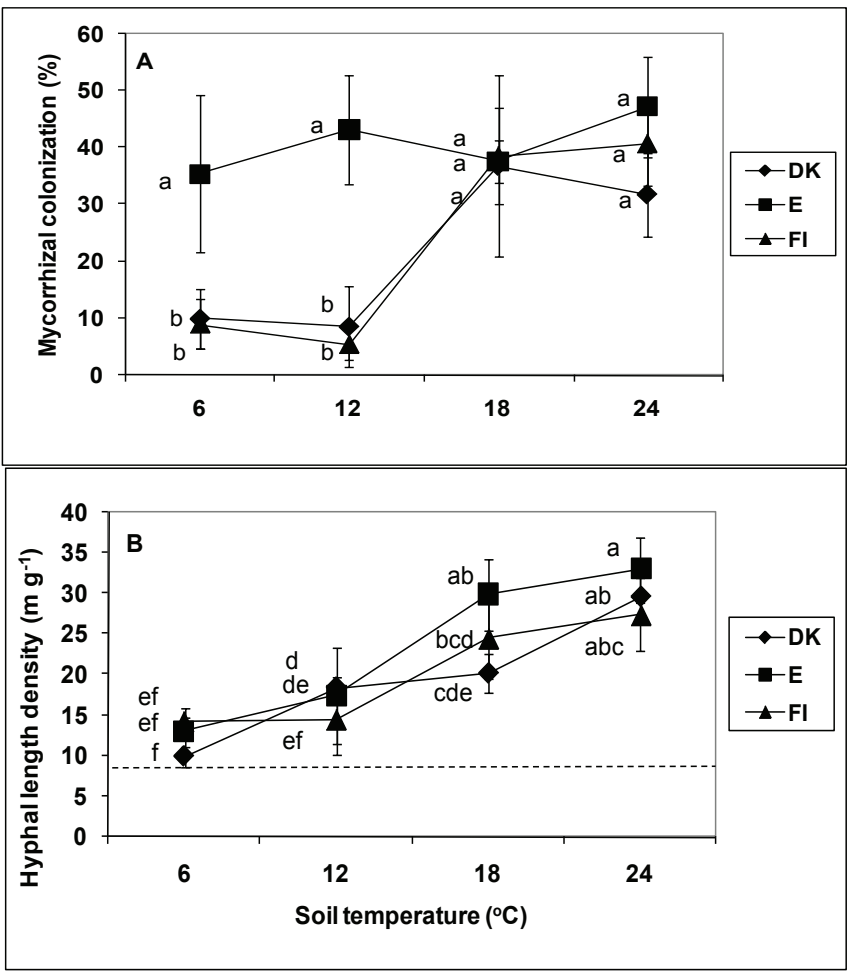

Fig. 3. Mycorrhizal colonization percentages in roots (A) and hyphal length density in soil (B) means (+ $\mathrm{SE})$ for the isolate $\mathrm{x}$ soil temperature treatment combinations. $\mathrm{DK}=$ isolate from Denmark, $\mathrm{E}=$ isolate from Spain, and $\mathrm{FI}=$ isolate from Finland. Significantly different $p<0.05$ ) means for the isolate $\mathrm{x}$ soil temperature interactions are marked with small letters. The dotted line shows the mean of the background level of hyphae present in the steam-sterilized soil before the experiment. 


\section{AGRICULTURAL AND FOOD SCIENCE}

M. Gavito \& C. Azcón-Aguilar (2012) 21: 2-11

The results provided clear evidence suggesting that there is no adaptation to low soil temperature in these AMF isolates. As previously reported for single AMF Danish isolates and native communities and results from in vitro cultures with isolates from contrasting regions of the world (Gavito et al. 2003, Gavito et al. 2005), these three isolates of the same AMF species showed low capacity to develop an external mycelium at temperatures below $12^{\circ} \mathrm{C}$ regardless of the temperatures they normally experienced in their original habitats.

The effects of the soil temperature treatments on fungal development were in this case not confused by differential effects of the fungal isolates on plant development so the differences observed can be attributed solely to soil temperature effects on aspects of the host and fungus physiology not related to plant growth. Despite a slight but significant increase in shoot:root ratio when plants were inoculated with the Danish isolate, the effects of the fungal isolates on host biomass and the development of the three isolates were strikingly similar.

Shoot, root, intraradical colonization and extraradical colonization development did not respond uniformly to the soil temperature treatments: 1) shoot biomass increased steadily between 6 and $18{ }^{\circ} \mathrm{C}, 2$ ) root biomass increased between 12 and $24^{\circ} \mathrm{C}$, 3) intraradical colonization at the different temperatures was isolate dependent, and 4) extraradical mycelium development increased steadily between 6 and $24{ }^{\circ} \mathrm{C}$ soil temperature for all AMF isolates. Therefore, there is a differential response to temperature among the plant and fungal components that make the result for the mycorrhizal symbiosis, as a whole, likely a combination of these responses. That is, optimal growth would likely be achieved in a temperature range which is favorable to all components.

The two Nordic AMF isolates rarely grow at temperatures above $15^{\circ} \mathrm{C}$ as indicated by the soil temperature regimes (Cryic and Frigid) of their original environments and as documented by extensive continuous measurements conducted all year round near soil surface, the warmest layer in the summer (http://www. $\mathrm{mm}$.helsinki.fi/core/data.htm ). The Spanish isolate that rarely experiences soil temperatures below $10^{\circ} \mathrm{C}$ was surprisingly more able to colonize the roots at these temperatures but formed equally low external mycelium as the Nordic isolates. The scarcity of good and reliable soil temperature data sets that allow proper interpretation of potential limitations for mycorrhizal performance is however a common problem and the design of appropriate management programs that make the best use of the most favorable soil temperature periods will be hampered by this lack of knowledge. Under the pressure of a rapidly changing climate and its evident consequences on plant production and plant productivity we should soon start by generating this important foundation of basic data.

Altogether results strongly suggest temperatures below $15^{\circ} \mathrm{C}$ limit the development of many arbuscular mycorrhizal fungi and occasional tolerance to low temperatures found in some isolates is more likely associated to genetic variation and plasticity than to environmental adaptation. The Spanish isolate seemed more plastic than the Nordic isolates likely because this is the isolate that is exposed to large variations of up to $25^{\circ} \mathrm{C}$ in mean soil temperature during the year and up to $35^{\circ} \mathrm{C}$ difference between the minimum and maximum values. The Nordic isolates, in turn, are from more homogeneous cold environments where the annual variation of the mean temperatures is less than $15^{\circ} \mathrm{C}$ with minimum and maximum temperatures differing by $20^{\circ} \mathrm{C}$ at the most. Our isolates had been propagated for a similar number of cycles, 4-6, under the average greenhouse or growth room temperatures above $18{ }^{\circ} \mathrm{C}$ that are used to grow most plants. There is a possibility that the isolates used in our study had been acclimated or had begun to undergo either phenotype or genotype changes as a consequence of the propagation cycles under mild soil temperatures they had been through before we started the experiment. Ehinger et al. 


\section{AGRICULTURAL AND FOOD SCIENCE}

M. Gavito \& C. Azcón-Aguilar (2012) 21: 2-11

(2009) showed some evidence for such changes after 4-8 propagation cycles that might result in consistent directional changes under certain growth conditions such as $\mathrm{P}$ availability, but no data are available so far suggesting that temperature acclimation or environmental selection for warm temperatures can occur after a few propagation cycles.

The fact that a freshly collected native AMF community from a Danish agricultural soil, including presumably several species adapted to cold soil, was not able to develop a mycelial network below $15{ }^{\circ} \mathrm{C}$ (Gavito et al. 2003) points to a physiological limit where acclimation or environmental selection for cold tolerance are unlikely. Soil has a large buffering capacity and plant and snow cover contributes to temperature insulation (Yli-Halla and Mokma 1998) but soils in the Nordic and other regions with cold climate have soil temperature regimes that suggest strong limitations for the development of AMF, especially of the extraradical mycelium. These physiological limitations seem complex and do not seem related to carbon limitation (Gavito et al. 2005) as it is mainly the extraradical mycelium that grows poorly at low temperatures and a C-limitation should affect both the intra- and extraradical mycelium.

Since the extraradical mycelium is the one enabling nutrient and water uptake for the functionality of the symbiosis and soil functions related to particle aggregation and nutrient cycling, its poor development may conflict with the functionality of the AM symbiosis in these environments. In the absence of the searching external phase on charge of these functions there may be little compensation, if any, for the carbon drain to AMF that are still able to colonize a small part of the root sytem and feed from it. Protection from pathogen attack and sink effects that stimulate photosynthetic rates might be some compensation but they seem also unlikely to be efficient when there is little mycorrhizal development.

Ruotsalainen and Kytoviita (2004) and Kytoviita (2005) have shown the impairment of the symbiosis in Arctic environments that are good, extreme examples of this functionality conflict. Tillage practices that drastically disrupt mycorrhizal mycelium networks might be particularly harmful in conditions where establishing a completely new mycelium network so strongly limited by low soil temperatures and the cost of feeding a symbiont constructing a new mycelium might be too large for a plant that is also limited in its carbon assimilation capacity by the low temperatures. Under these conditions and using conventional agricultural practices obviating this problem mycorrhizal associations are more likely to become a burden than an asset. In natural environments without management the cost of the symbiosis is likely much lower because the intact mycorrhizal networks regain functionality and reconnect to plants shortly after soils start to warm in the summer (Gavito and Miller 1998, Addy et al. 1998) and can provide efficient uptake, pathogen defence, soil aggregation and nutrient cycling functions as well as a strong sink strength to stimulate photosynthesis and compensate their use of plant carbon.

All this information suggests that AMF have a very narrow window to develop during the year in cold regions of the world and that this window ought to be well exploited during the summer periods, especially in agroecosystems where management of the symbiosis is aimed at improving crop performance and soil quality.

\section{Acknowledgements}

We thank Mauritz Vestberg and John Larsen for providing the Nordic isolates. Mayra E. Gavito thanks the Marie Curie Postdoctoral Fellowship Program of the European Commission for financial support. 


\section{AGRICULTURAL AND FOOD SCIENCE}

M. Gavito \& C. Azcón-Aguilar (2012) 21: 2-11

\section{References}

Addy, H.D., Boswell, E.P. \& Koide, R.T. 1998. Low temperature acclimation and freezing resistance of extraradical VA mycorrhizal hyphae. Mycological Research 102: 582-586.

Baldocchi, D.D., Black, T.A., Curtis, P.S., Falge, E., Fuentes, J.D., Garnier, A., Gu, L., Knohl, A., Pilegaard, K., Schmid, H.P., Valentini, R., Wilson, K., Wofsy, S., Xu, L., Yamamoto, S. 2005. Predicting the onset of net carbon uptake by deciduous forests with soil temperature and climate data: a synthesis of the FLUXNET data. International Journal of Biometeorology 49: 377-387.

Daniels-Hetrick, B.A. \& Bloom, J. 1984. The influence of temperature on colonization of winter wheat by vesiculararbuscular mycorrhizal fungi. Mycologia 76: 953-956.

Delgado, R., Martín-Gracia, J.M., Calero, J., Casares-Porcel, M., Tito-Rojo, J. \& Delgado, G. 2007. The historic manmade soils of the Generalife garden (La Alhambra, Granada, Spain). European Journal of Soil Science 58, $215-228$.

Ehinger, M., Koch, A.M., Sanders, I., A. 2009. Changes in arbuscular mycorrhizal fungal phenotypes and genotypes in response to plant species identity and phosphorus concentration. New Phytologist 184: 412-423.

Fitter, A.H., Heinemeyer, A.,\& Staddon, P.L. 2000. The impact of elevated $\mathrm{CO}_{2}$ and global climate change on arbuscular mycorrhizae: a mycocentric approach. New Phytologist 147: 179-187.

Gavito, M. E. \& Miller, M. H. 1998. Early phosphorus nutrition, mycorrhizae development, dry matter partitioning and yield of maize. Plant and Soil 199: 177-186.

Gavito, M. E., Rouhier, H., Olsson, P. A., Medina-Peñafiel, A., Jakobsen, I., Bago, B.\& Azcón-Aguilar, C. 2005. Temperature constraints on the growth and functioning of root organ cultures with arbuscular mycorrhizal fungi. New Phytologist 168: 179-188.

Gavito, M.E., Schweiger, P. \& Jakobsen, I. 2003. P uptake by arbuscular mycorrhizal hyphae: effect of soil temperature and atmospheric $\mathrm{CO}_{2}$ enrichment. Global Change Biology 9: 106-116.

Grey, W.E. 1991. Influence of temperature on colonization of spring barleys by vesicular arbuscular mycorrhizal fungi. Plant and Soil 137: 181-190.

Heinemeyer, A. \& Fitter, A.H. 2004. Impact of temperature on the arbuscular mycorrhizal (AM) symbiosis: growth responses of the host plant and it AM fungal partner. Journal of Experimental Botany 55: 525-534.

Heinemeyer, A., Ridgway, K.P., Edwards, E.J., Benham, D.G., Young, P.W. \& Fitter, A.H. 2003. Impact of soil warming and shading on colonization and community structure of arbuscular mycorrhizal fungi in roots of a native grassland community. Global Change Biology 10: 52-64.

Jakobsen, I., Abbott, L. K. \& Robson, A. D. 1992. External hyphae of vesicular-arbuscular mycorrhizal fungi associated to Trifolium subterraneum L. 1. Spread of hyphae and phosphorus inflow into roots. New Phytologist 120: $371-380$.

Kormanick, P. P. \& McGraw, A.C. 1982. Quantification of vesicular-arbuscular mycorrhiza in plant roots. In: Schenck, N. C. (ed.). Methods and principles of mycorrhizal research. St. Paul, USA: American Phytopathological Society. p. $37-45$.

Kytoviita, M. M. 2005. Asymmetric symbiont adaptation to Arctic conditions could explain why high Arctic plants are nonmycorrhizal. FEMS Microbiology Ecology 53: 27-32.

Liu, A., Wang, B. \& Hamel, C. 2004. Arbuscular mycorrhizal colonization and development at suboptimal root zone temperature. Mycorrhiza 14: 93-101.

McGonigle, T. P., Miller, M. H., Evans, D. G., Fairchild, G. L. \& Swan, J. A. 1990. A new method which gives an objective measure of colonization of roots by vesicular-arbuscular mycorrhizal fungi. New Phytologist 15: 495-501.

Moreno-Rueda, G., Ruiz-Ruiz, A., Collantes-Martin, E. \& Ramón-Arrebola, J. 2009. Relative importance of humidity and temperature on microhabitat use by land snails in arid versus humid environments. In: Arid Environments and Wind Erosion (Fernández-Bernal, A. \& De la Rosa, M.A., Eds.). Nova Science Publishers. p. 331-346.

Pilegaard, K., Hummelshøj, P., Jensen, N.O. \& Chen, Z. 2001. Two years of continuous $\mathrm{CO}_{2}$ eddy-flux measurements over a Danish beech forest. Agricultural and Forest Meteorology 107: 29-41.

Rillig, M.C., Wright, S.F., Shaw, M.R. \& Field, C.B. 2002. Artificial climate warming possitively affects arbuscular mycorrhizae but decreases soil aggregate water stability in an annual grasland. Oikos 97: 52-58.

Ruotsalainen, A. L. \& Kytoviita, M. M., 2004. Mycorrhiza does not alter low temperature impact on Gnaphalium norvegicum. Oecologia 140: 226-233. 


\section{AGRICULTURAL AND FOOD SCIENCE}

M. Gavito \& C. Azcón-Aguilar (2012) 21: 2-11

Staddon, P.L., Heinemeyer, A. \& Fitter, A.H. 2002. Mycorrhizae and global environmental change: research at different scales. Plant and Soil 244: 253-261.

Staddon, P.L., Thompson, K., Jakobsen, I., Grime, J.P., Askew, A.P. \& Fitter, A.H. 2003. Mycorrhizal fungal abundance is affected by long-term climatic manipulations in the field. Global Change Biology 9: 186-194.

Wang, B., Funakoshi, D.M., Dalpé, Y.\& Hamel, C. 2002. Phosphorus-32 absorption and translocation to host plants by arbuscular mycorrhizal fungi at low root-zone temperature. Mycorrhiza 12: 93-96.

Yli-Halla, M. \& Mokma, D. L. 1998. Soil temperature regimes in Finland. Agricultural and Food Science in Finland 7: 507-512. 